\title{
New drugs in lung cancer
}

\author{
D C Talbot, I E Smith
}

The best hope for improved treatment of lung cancer lies in the development of effective new drugs. Lung cancer is the main cause of cancer related death in Britain, accounting for $17 \%$ of all new registered cases of cancer and $25 \%$ of cancer deaths. ${ }^{1}$ Over $90 \%$ of patients with lung cancer die of their disease. Despite dramatic developments with cytotoxic chemotherapy for some malignancies over the last four decades, very little impact has been made on cure rate for patients with lung cancer. This is brought into perspective by comparing the change in five year survival rates of lung cancer and childhood acute lymphoblastic leukaemia over the last two decades. The five year survival rate for acute lymphoblastic leukaemia has increased from $8 \%$ to $70 \%$ as a result of improved treatment with cytotoxic drugs, whereas the five year survival rate for lung cancer for all ages remains unchanged at $8 \%$, with over $\mathbf{4 0} 000$ deaths each year in the United Kingdom alone.

Prospects are bleak for all histological subtypes. Small cell lung cancer is very chemosensitive in its initial clinical stages; treatment with appropriate chemotherapy does improve survival, but only to around 10-15 months for patients with limited disease and to 7-11 months for those with extensive disease. Deaths from small cell lung cancer continue to occur beyond two years from diagnosis and a recent report gave a dismal five year survival rate of only $2 \cdot 5 \% .^{2}$ For patients with non-small cell lung cancer surgery offers the best chance of cure, but by the time the diagnosis is made most patients have inoperable disease. The role of chemotherapy in the management of advanced non-small cell lung cancer is controversial. Modest response rates of $25-50 \%$ are achieved with combination chemotherapy containing cisplatin, but the response usually lasts only a few months and the survival benefit is marginal at most. ${ }^{3}$

Most drugs in use today have been developed by empirical means with extensive screening processes. Many of the biochemical and pharmacological properties of a new drug are not determined until some time after the drug has achieved wide clinical application. Technological advances and a fuller understanding of the biology of cancer may allow us to identify specific molecular targets for which to design new drugs. An encouraging development is the characterisation of many of the receptors for autocrine and paracrine growth factors for small cell lung cancer and of the events occurring after activation of the receptors. Other possible drug targets include the DNA replicative machinery, the genes for tumour promoters and suppressors and the tumour cell cycle regulatory genes, and the transcripts and products of these genes.

\section{Small cell lung cancer}

WHEN TO ASSESS NEW DRUGS

Small cell lung cancer is one of the most chemosensitive of the solid tumours, and many drugs have activity against this form of lung cancer. ${ }^{4}$ Much clinical research effort has gone into investigating combination chemotherapy, alternating chemotherapy and high dose chemotherapy with autologous bone marrow rescue, yet the median survival has been prolonged by only a few months. The rapid recurrence seen in most patients after initial tumour regression indicates that the key problem is multidrug resistance, either innate or acquired. This points to an important question in the development of drugs: when should new drugs be assessed? The conventional approach has been to test new drugs only after conventional chemotherapy has failed. Not unexpectedly, in this multidrug resistant environment results are much worse than when the same agent is tested in previously untreated patients. Etoposide when given as a single agent had a response rate of $80 \%$ in untreated patients ${ }^{5}$ but only $10 \%$ in patients previously treated with cytotoxic drugs. ${ }^{6}$ Similarly, teniposide had a reported $90 \%$ response rate in untreated patients, ${ }^{7}$ compared with $6 \%$ in $\omega$ previously treated patients. $^{8}$ In our initial $\underset{\nabla}{2}$ studies with carboplatin at the Royal Marsden Hospital we found response rates of $60 \%$ for untreated patients, compared with $19 \%$ for treated patients. ${ }^{9}$

Testing new drugs in previously untreated patients clearly minimises the risk of rejecting a clinically useful drug because it lacks efficacy in patients with resistant disease. On the other hand, this approach is not straightforward because the survival and quality of life of the patient may be put in jeopardy if an inactive drug is tested in untreated patients. In a phase II trial of oral idarubicin in 21 untreated patients with extensive disease a response rate of only $14 \%$ was observed. Despite a policy of switching promptly to cyclophosphamide, vincristine, and etoposide, only 14 patients were

\footnotetext{
D C Talbot

Reprint requests to: Dr Talbot

Lung Unit,

Hospital, Sutton

Surrey SM2 5PT
} 
well enough to do this and the response rate was low at $19 \%$, with a short median survival of six months. ${ }^{10}$ The outcome was the same in two other trials of similar design in patients with extensive disease: median survival times of only seven weeks were achieved with triglycidylurazole $^{11}$ and eight weeks with mitoxantrone ${ }^{12}$ - similar to the survival expected for untreated patients with extensive small cell lung cancer. If the agent under investigation has low activity then the patient is effectively receiving no treatment, and the chance for useful palliation with conventional chemotherapy is lost.

What therefore is the best way to evaluate new drugs in small cell lung cancer? An important prerequisite is for patients receiving a trial drug to have a good performance status without metastatic disease that is currently life threatening. Several methods are then possible.

The first is to add the drug under investigation to an otherwise standard combination and compare this regimen with the standard combination alone. When this method was used to evaluate cisplatin, 100 patients with extensive small cell lung cancer were randomised to receive etoposide, cyclophosphamide, doxorubicin, and vincristine with or without cisplatin. The objective response rate was $48 \%$ in the four drug combination and $83 \%$ in the five drug combination containing cisplatin. ${ }^{13}$ This method overcomes the problem of testing drugs with low activity but has a number of disadvantages. Because most combinations now give high response rates, large numbers of patients need to be randomised in this kind of study if an increase in response resulting from the new agent is to be seen. Furthermore, the activity of the drug as a single agent cannot be determined by this means.

A second approach would be to lower the threshold for determining activity to below $10 \%$ when a new drug is assessed in previously treated patients. This would necessarily increase the number of patients required for accrual to maintain satisfactory confidence limits. After reviewing 97 phase II studies in small cell lung cancer, Cohen concluded that it was not essential to study previously untreated patients to assess activity with a new drug. ${ }^{14}$

A third technique would be to randomise previously untreated patients to receive standard first line induction drugs or the phase II drug. Patients with stable or progressive disease after one or two cycles or progressive disease after an initial response would receive conventional salvage chemotherapy. This method was used in the Eastern Cooperative Oncology Group phase II study of menogaril. The standard induction drugs were cyclophosphamide, doxorubicin (Adriamycin), and vincristine, with etoposide and cisplatin as salvage chemotherapy. Menogaril was found to be inactive in terms of the response criteria; the estimated median survival times were 42 weeks for patients receiving cyclophosphamide, doxorubicin, and vincristine and 38 weeks for those having menogaril, but the differences were not significant. ${ }^{15}$

We are currently investigating a variant of this approach, in which patients are randomised to receive standard induction treatment or the study drug for a maximum of two cycles only. Patients with progressive disease after one cycle of the study drug are immediately switched to the standard combination and all other patients on the new drugs are automatically switched to standard drugs after two cycles irrespective of response. This enables the response to be appropriately evaluated without, we hope, jeopardising the chance of long term survival with conventional chemotherapy; the randomised nature of the trial allows us to confirm whether this is indeed the case.

\section{NEW DRUGS}

The phase II studies of single agents in the last three years are shown in table 1 ; about half were performed on previously untreated patients. One of the most active agents developed recently is the water soluble semisynthetic camptothecin analogue CPT11. Camptothecin is a plant alkaloid isolated from the Asian tree

Table 1 Clinical trials of new drugs (single agents) for small cell lung cancer

\begin{tabular}{|c|c|c|c|c|c|c|c|c|c|}
\hline Drug & Dose and schedule & $\begin{array}{l}\text { Not } \\
\text { previously } \\
\text { treated }\end{array}$ & $\begin{array}{l}\text { Previously } \\
\text { treated }\end{array}$ & $\begin{array}{l}\text { Total } \\
\text { No } \\
\text { evaluable }\end{array}$ & $C R$ & $P R$ & $\begin{array}{l}\text { Response } \\
(\%)\end{array}$ & $\begin{array}{l}\text { Median } \\
\text { duration of } \\
\text { survival } \\
(w)\end{array}$ & Reference \\
\hline Amonafide & $300 \mathrm{mg} / \mathrm{m}^{2} \mathrm{IV} \mathrm{d} 1-5 \mathrm{q} 21 \mathrm{~d}$ & 13 & 0 & 12 & 0 & 0 & 0 & 31 & Evans $^{54}$ \\
\hline Epirubicin & $120 \mathrm{mg} / \mathrm{m}^{2} \mathrm{IV} \mathrm{q} 21 \mathrm{~d}$ & 80 & 0 & 71 & 4 & 30 & 48 & 30 & Eckhardt $^{21}$ \\
\hline $\begin{array}{l}\text { Methylglyoxal } \\
\text { bisgluanglhydrazone }\end{array}$ & $\begin{array}{l}500 \mathrm{mg} / \mathrm{m}^{2} \mathrm{IV} \mathrm{q} 7 \mathrm{~d} \times 4 \mathrm{w} \\
\text { then q } 14 \mathrm{~d}\end{array}$ & 0 & 24 & 24 & 0 & 1 & 4 & - & Simon $^{55}$ \\
\hline Sulofenur & $\begin{array}{l}800 \mathrm{mg} / \mathrm{m}^{2} \mathrm{PO} \mathrm{d} \mathrm{l}-5 \\
\times 3 \mathrm{w} \mathrm{q} 28 \mathrm{~d}\end{array}$ & 9 & 0 & 9 & 0 & 0 & 0 & - & Shepherd ${ }^{56}$ \\
\hline Interleukin-2 & $\begin{array}{l}4.5 \times 10^{6} \mathrm{MU} / \mathrm{m}^{2} / \mathrm{d} \\
\text { IV for } 96 \mathrm{~h} \mathrm{q} 7 \mathrm{~d} \times 4^{\star}\end{array}$ & 0 & 67 & 10 & 2 & 1 & 30 & - & Clamon $^{30}$ \\
\hline Spirogermanium & $\begin{array}{l}125-200 \mathrm{mg} / \mathrm{m}^{2} \mathrm{IV} \text { tiw } \times 2 \mathrm{w} \\
\text { reducing to once weekly }\end{array}$ & 15 & 0 & 15 & 0 & 0 & 0 & - & $\mathrm{Lad}^{57}$ \\
\hline Tiazofurin & $800 \mathrm{mg} / \mathrm{m}^{2}$ IV daily $\times 5 \mathrm{q} 28 \mathrm{~d}$ & 0 & 14 & 14 & 0 & $\mathbf{0}$ & 0 & - & Holoye $^{58}$ \\
\hline Teniposide & $\begin{array}{l}120-140 \mathrm{mg} / \mathrm{m}^{2} \\
\text { IV d } 1,3,5 \mathrm{q} 21 \mathrm{~d}\end{array}$ & 12 & 36 & 44 & 4 & 11 & 34 & 34 & Giaccone $^{59}$ \\
\hline Iproplatin & $300 \mathrm{mg} / \mathrm{m}^{2} \mathrm{IV} \mathrm{q} 28 \mathrm{~d}$ & 0 & 16 & 16 & 0 & 0 & 0 & - & Kramer $^{60}$ \\
\hline Menogaril & $200 \mathrm{mg} / \mathrm{m}^{2}$ IV q $28 \mathrm{~d}$ & 40 & 0 & 40 & 0 & 2 & 5 & 38 & Ettinger $^{01}$ \\
\hline Mitozolomide & $70-90 \mathrm{mg} / \mathrm{m}^{2}$ PO q $42 \mathrm{~d}$ & 11 & 9 & 18 & 0 & 5 & 28 & - & Harding $^{62}$ \\
\hline CPT-11 & $100 \mathrm{mg} / \mathrm{m}^{2} \mathrm{IV}$ q $7 \mathrm{~d}$ & 8 & 33 & 35 & 2 & 7 & 37 & - & Negoro $^{18}$ \\
\hline Ifosfamide & $5 \mathrm{~g} / \mathrm{m}^{2} \mathrm{IV}$ q $21 \mathrm{~d}$ & 0 & 14 & 14 & 0 & 6 & 43 & - & Cantwell $^{26}$ \\
\hline
\end{tabular}

*All patients given induction chemotherapy followed by interleukin-2 for patients with assessable disease.

IV—intravenously; $d-$ day; q-every; w-week; PO-orally; tiw-three times a week; CR—complete response; PR—partial response. 
Camptotheca acuminata and, although it is active against experimental tumours, its clinical use is limited by severe haemorrhagic cystitis and low respone rates. ${ }^{16}$ CPT 11 is a potent inhibitor of topoisomerase $\mathrm{I}$, has encouraging preclinical and antitumour activity, and in man is better tolerated than the parent compound. Phase I studies with single doses have shown that it has a maximum tolerated dose of $250 \mathrm{mg} / \mathrm{m}^{2}$, the dose limiting toxicity being myelosuppression. Other adverse reactions include alopecia and gastrointestinal toxicity but not haemorrhagic cystitis. ${ }^{17}$ The results of the first phase II study of CPT11 in small cell lung cancer are encouraging. The 41 patients received CPT 11 $100 \mathrm{mg} / \mathrm{m}^{2}$ by intravenous infusion over 90 minutes every week with dose reduction for neutropenia. Two of 27 previously treated evaluable patients had a complete response and seven had a partial response (objective response $33 \%$ ). Of eight evaluable previously untreated patients four had a partial response. The median duration of response was 50 days. ${ }^{18}$ Pharmacokinetic studies of CPT11 and its active metabolic $\mathrm{SN} 38$ showed that elimination is triphasic, with a long terminal half life of 18 hours, which is clearly an advantage for a drug active in $S$ phase. ${ }^{19}$ Other camptothecin analogues are being evaluated, including topotecan (SKF104864), which is currently undergoing phase I clinical trials.

Much of the effort put into development of drugs for small cell lung cancer has focused on the assessment of analogues of existing active groups of drugs, notably the anthracyclines and epipodophyllotoxins. Epirubicin (4-epidoxorubicin) has been in clinical use for some years but interest recently has been focused on dose escalation studies in patients with solid tumours. The clinical trials group of the National Cancer Institute of Canada gave epirubicin $100-120 \mathrm{mg} / \mathrm{m}^{2}$ intravenously every three weeks to patients with extensive disease. An objective response rate of $50 \%$ was achieved, with a median survival of 35 weeks. ${ }^{20}$ Adverse effects included, predictably, moderate myelosuppression, alopecia, nausea, and vomiting but not cardiotoxicity. A similar response rate was reported by Eckhardt in $\mathbf{8 0}$ previously untreated patients receiving 120 $\mathrm{mg} / \mathrm{m}^{2}$ every three weeks. In this series one patient developed congestive cardiac failure, which was fatal. ${ }^{21}$

Despite the synthesis of many new derivatives of the epipodophyllotoxins, etoposide and teniposide remain the most effective members of this class of cytotoxic agent. Epipodophyllotoxins in combination with other drugs, notably compounds containing platinum, are currently one of the most active combinations for treatment of small cell lung cancer. We now know more about their mechanism of action, which is thought to be interaction with topoisomerase II and DNA, causing formation of stable DNA-enzyme complexes. With the help of computer assisted molecular modelling it may be possible to design new analogues with greater specificity for binding to topoisomerase II and to DNA. ${ }^{22}$ The epipodophyllotoxins are phase specific drugs acting in the $G_{2}$ phase of the cell cycle. Their efficacy depends on the schedule of administration. The response and survival of patients with small cell lung cancer is better when etoposide is given as repeated daily infusions of $100 \mathrm{mg} / \mathrm{m}^{2}$ for five days than as a single infusion of $500 \mathrm{mg} / \mathrm{m}^{2}{ }^{23}$ The bioavailability of etoposide after oral administration is about $\mathbf{5 0 \%}$, which makes it a good candidate for repeated low dose oral administration. This has the potential advantages of easy administration and acceptable toxicity. ${ }^{24}$

Ifosfamide also appears to be well suited to combination chemotherapy in the treatment of small cell lung cancer as it is less myelosuppressive than its parent compound, cyclophosphamide and is not cross resistant with standard alkylating agents, and its dose limiting toxicity, haemorrhagic cystitis, can be abrogated by Mesna without loss of efficacy.${ }^{25}$ It has activity as a single agent in patients previously treated with etoposide, vincristine, and doxorubicin, ${ }^{26}$ though response rates appear to be reduced if prior treatment includes cyclophosphamide. ${ }^{27}$ We reported a study at the Royal Marsden Hospital using ifosfamide in combination with carboplatin and etoposide, with a high response rate of $94 \%$ and a median survival of 19 months. ${ }^{28}$

Drugs containing platinum, and in particular carboplatin, continue to play a prominent part in the management of small cell lung cancer. ${ }^{29}$ The major dose limiting toxicity of carboplatin is myelosuppression, and it is therefore a good candidate for dose escalation studies in combination with haematopoietic growth factors, including interleukin-3. Several promising new platinum analogues are being developed, but their clinical efficacy in small cell lung cancer has still to be assessed.

Biological response modifiers represent a new modality in cancer treatment. Preliminary results are becoming available from studies in small cell lung cancer. A phase II trial of interleukin-2 in extensive disease is currently in progress. ${ }^{30}$ Previously untreated patients were initially given four cycles of doxorubicin, cyclophosphamide, etoposide, and platinum. Four weeks later all patients not achieving a complete response received a continuous infusion of interleukin-2 $\left(4.5 \times 10^{6} \mathrm{mU} / \mathrm{m}^{2}\right.$ a day) for four days repeated weekly for four weeks. Of the 67 patients, only 10 were treated with interleukin-2; three had an objective response, including two with complete remissions. Toxicity was severe enough to require discontinuation of treatment in at least $10 \%$ of patients. Dose limiting toxicity included hypotension, haemolysis, renal failure, hepatic dysfunction, and allergy. The long term role, if any, for interleukin-2 in the treatment of small cell lung cancer remains to be determined. The role of interferon- $\gamma$ as maintenance treatment is being evaluated in an EORTC trial in patients achieving a complete response to conventional chemotherapy.

Non-small cell lung cancer

Non-small cell lung cancer is considerably 
more chemoresistant than small cell lung cancer and the role of chemotherapy in its management remains controversial. Only a few cytotoxic drugs have even modest single agent activity in non-small cell lung cancer. The most active include ifosfamide, vindesine, vinblastine, mitomycin $\mathrm{C}$, and cisplatin, all with average response rates of around $20 \%$. $^{3}$ Combination chemotherapy regimens containing cisplatin achieve response rates of $30-50 \%$, but the response is of short duration and real clinical benefit is uncertain. Consequently there is less of a problem in the timing of treatment with new drugs for patients with non-small cell lung cancer than with small cell lung cancer. It is our view that results with conventional drugs are not sufficiently good to justify their use as orthodox treatment and our practice is therefore to offer new drugs as first line treatment in patients who are both fit enough to receive this and who are anxious to have such treatment on an experimental basis.

Table 2 shows several new agents that have recently been tested in patients with non-small cell lung cancer. False positive results of phase II studies are often due to bias from low accrual rates, high exclusion rates for evaluation of response, and premature publication. On the other hand, drugs may be wrongly rejected on the grounds of low activity because the schedule was not optimal, as was the case for ifosfamide. ${ }^{3}$ Several studies have been reported in the last three years, carried out in both previously treated and "chemotherapy naive" patients.

Camptothecin analogues show considerable activity in early clinical trials. A Japanese study has had a response rate of $41 \%$ in previously untreated patients, but this was based on data from only 22 evaluable patients out of the 41 who entered the study. ${ }^{31}$ Leucopenia, nausea and vomiting, and diarrhoea occurred in about half the patients. This group of drugs clearly warrants further clinical evaluation.

Navelbine is a semisynthetic vinca alkaloid that acts by inhibition of tubulin polymerisation. It has a long terminal half life by comparison with the other vinca alkaloids and a large volume of distribution, suggesting high tissue uptake, which is most striking in the lung. A $33 \%$ objective response rate was seen in 69 previously untreated patients evaluable for response, out of the original 78 ; and similar response rates were seen for squamous cell carcinoma and adenocarcinoma. ${ }^{32}$ Of particular importance, the incidence of neuropathy (7\%) was lower than with vincristine or vindesine. The dose limiting toxicity was granulocytopenia, but recovery time was short. These results are encouraging and warrant further

Table 2 Clinical trials of new drugs (single agents) for non-small cell lung cancer

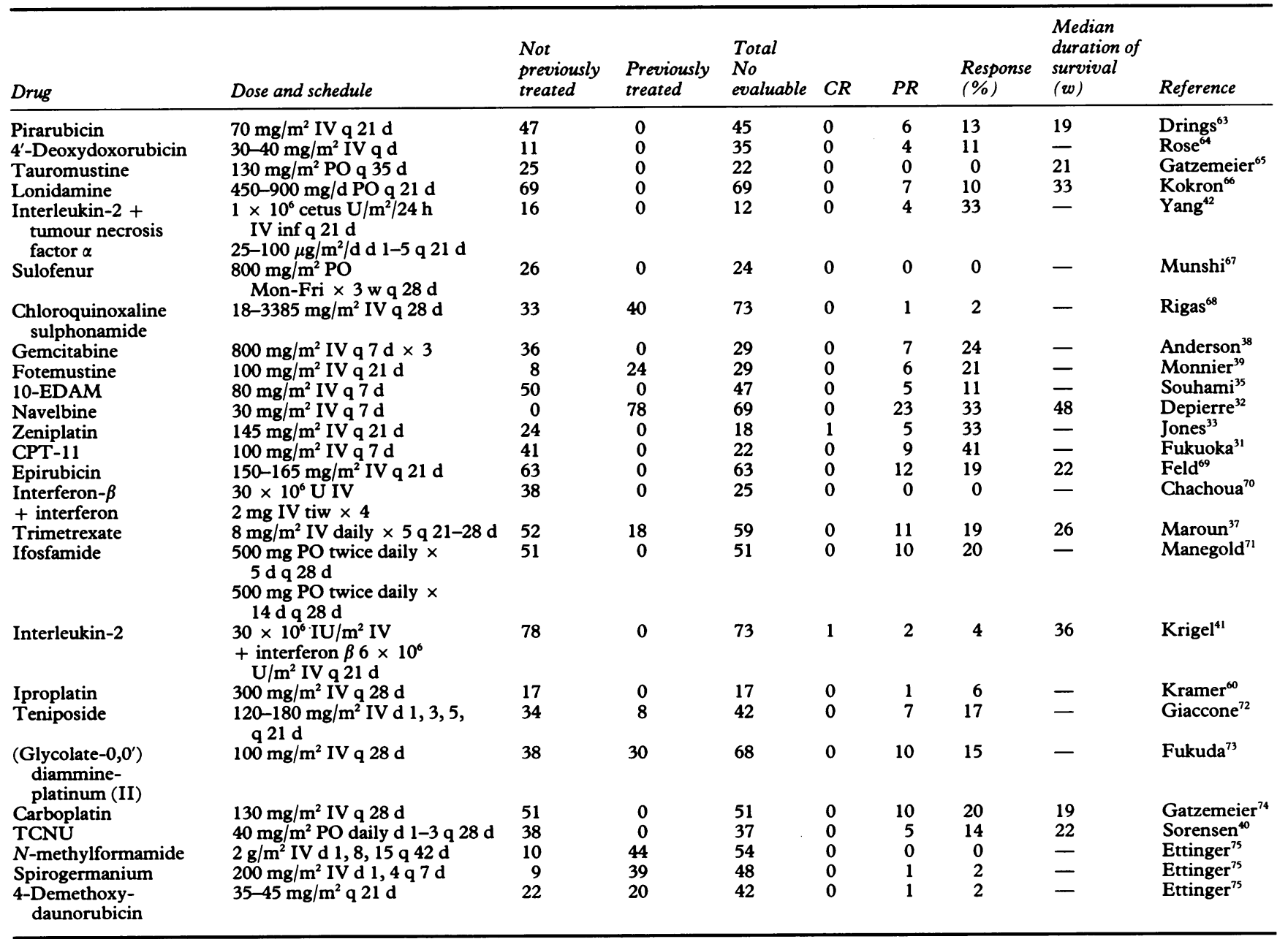

*All patients given induction chemotherapy followed by interleukin-2 for patients with assessable disease. 
evaluation of navelbine in combination with other drugs.

Zeniplatin is a water soluble, third generation platinum analogue active against murine tumour models and in human tumour xenografts. In preclinical studies it had a superior therapeutic dose ratio to that of cisplatin. We have given this drug to 29 previously untreated patients with advanced non-small cell lung cancer, six of whom achieved an objective response. In general, zeniplatin was well tolerated, apart from neutropenia, but one patient developed renal failure thought to be due to the drug. ${ }^{33}$

At least three new antimetabolites have activity as single agents in non-small cell lung cancer. 10-EDAM (10-ethyl-5-deaza-aminopterin) is a methotrexate analogue that has a modification at the $N-10$ position and is a potent inhibitor of dihydrofolate reductase. It has better cellular uptake and polyglutamation and greater preclinical antitumour activity than methotrexate. Early phase II trials had a promising response rate of $32 \%$ in 20 previously treated patients ${ }^{34}$ but, as so often happens, the response rate has fallen as larger trials have been performed. ${ }^{35}$ Trimetrexate is a new lipophilic antifolate that differs from classical antifolates in that it is not polyglutamated but enters cells by a different mechanism and accumulates to give higher intracellular concentrations. The maximum tolerated dose varies widely among patients, depending on several factors, including serum albumin concentration; schedule, and presence or absence of hepatic metastases..$^{36}$ As a single agent it has only modest activity in non-small cell lung cancer. ${ }^{37}$ Preclinical studies, however, suggest that it may act synergistically with 5-fluorouracil and this combination may be worth evaluating.

The pyrimidine antimetabolite gemcitabine (difluorodeoxycytidine) is an analogue of cytosine arabinoside (Ara-c) and has preclinical activity in several murine and human tumour cell lines (including those resistant to Ara-c) and in lung xenografts. The side effects are schedule dependent fever and hypotension. It has moderate activity in non-small cell lung cancer, with a $24 \%$ partial response rate in 29 evaluable patients who had not previously had any treatment. ${ }^{38}$

Of three new alkylating agents that have been assessed, two have modest activity. Fotemustine is a chloronitrosourea that alkylates and carbamoylates DNA. An overall response rate of $21 \%$ was found in 29 evaluable patients, 24 of whom had had previous treatment. ${ }^{39}$ TCNU-(1-(2-chloroethyl)-3-2 (dimethylaminosulfonyl)-ethyl-1-nitrosourea)-is a water soluble nitrosourea, which given orally is reported to have a $14 \%$ response rate as a single agent in previously untreated patients. ${ }^{40}$ Phase II studies of some other agents with rather lower response rates are shown in table 2.

Studies on biological response modifiers are disappointing in non-small cell lung cancer. An objective response rate of $4 \%$ was achieved in 73 evaluable patients with metastatic non-small cell lung cancer who had been randomised to receive interleukin- $2\left(30 \times 10^{6} \mathrm{IU} / \mathrm{m}^{2}\right)$ or interleukin-2 plus interferon- $\beta\left(6 \times 10^{6} \mathrm{U} / \mathrm{m}^{2}\right)$ intravenously three times a week. There was no significant difference between the two groups, though the overall median survival of 35.6 weeks was longer than that seen in historical controls. ${ }^{41}$ In a small trial of 12 evaluable patients a $33 \%$ response rate was achieved with the combination of interleukin-2 and tumour necrosis factor $\alpha^{42}$

New targets and future directions for the treatment of lung cancer

New targets for treatment will, it is hoped, come from an increased understanding of the biology of tumour growth control. Several approaches are possible.

\section{ONCOGENES AND ANTI-ONCOGENES}

The proliferation rate of human lung cancer cell lines may be increased through overexpression of the myc family of proto-oncogenes. ${ }^{43}$ Any stage in proto-oncogene expression could ultimately be a target for therapeutic intervention. The phorbol esters are agents that induce monocyte differentiation but they also decrease c-myc transcription, which results in slower growth rates in leukaemic cell lines. Possibly a similar approach could inhibit the growth of lung cancer in vitro and perhaps eventually in the clinic.

A fundamental and probably early event in most types of lung cancer is a deletion in chromosome 3, principally in the 3p 14-23 region. ${ }^{44}$ This may represent a loss of a suppressor gene, resulting in the permissive expression of the malignant phenotype. The molecular biology of the $3 p$ deletion has not yet been fully worked out, but an enzyme encoded by the 3p 14-23 region, aminoacyclase $I$, is underexpressed in lung cancer and particularly in small cell lung cancer. ${ }^{45}$ Further studies should determine the function of this enzyme, which may represent a target for therapeutic manipulation.

\section{“ANTISENSE" TREATMENT}

Much "venture" capital is currently being invested in the development of antisense oligonucleotides. These are short, synthetic, single strand nucleotides containing sequences complementary to target messenger RNA or DNA. By virtue of the highly specific sequences of antisense oligonucleotides they can be used to block expression of defined oncogenes or oncogene products. Successful inhibition of c-myc expression with inhibition of cell proliferation has already been achieved in vitro in this way. ${ }^{46}$ There are many practical difficulties to be overcome with this approach in vivo; these include nuclease degradation of synthetic oligonucleotides and difficulties of cellular access. The possibilities of specifically targeted oligonucleotide drugs against oncogene expression in lung cancer are, however, exciting.

AUTOCRINE GROWTH CONTROL

Lung cancer, and in particular small cell lung cancer, is associated with the production of a series of autocrine growth factors that stimulate 
malignant cell proliferation. These include bombesin like peptides, such as the mammalian homologue of bombesin, gastrin releasing peptide, insulin like growth factor I and transferrin (see second article in this series, December 1991, p924). Our group, for example, has shown that insulin like growth factor $I$ is an autocrine growth factor in human small cell lung cancer and that in vitro tumour cell growth can be inhibited by monoclonal antibodies against insulin like growth factor I and its major receptor. ${ }^{47}$ This raises the possibility of antibody or oligopeptide analogue drugs directed against the receptor. Gastrin releasing peptide has also been shown to be an important growth factor for human small cell lung cancer. ${ }^{48} \mathrm{We}$ are currently investigating a group of 11-amino acid oligopeptide analogues of substance $P$, a sensory neurotransmitter, and looking at the effect of one on the growth of human small cell lung cancer xenografts. Some of these analogues are powerful inhibitors of human lung cancer growth in vitro and they are thought to act at least in part through inhibition of gastrin releasing peptide. Preliminary studies also show activity in xenografts. One agent might be subjected to clinical trial within the next two years.

\section{HAEMATOPOIETIC GROWTH FACTORS}

Several haematopoietic growth factors are now being used in the management of lung cancer and other malignancies to increase the rate of recovery from drug induced myelosuppression (see previous article in this series, p119). They should reduce treatment related toxicity and may enable larger doses of cytotoxic drugs to be given. ${ }^{49}$ Neutrophil recovery can be accelerated in a dose and schedule dependent manner with granulocyte colony stimulating factor or granulocyte macrophage colony stimulating factor..$^{50}$ Thrombocytopenia, however, is not affected by these agents. Newer haematopoietic growth factors, including interleukin-3, interleukin-1, and colony stimulating factor, have the potential for stimulating thrombopoiesis as well as granulopoiesis and may have a part to play in very high dose chemotherapy.

\section{IMPROVING QUALITY OF LIFE}

Despite its limited impact on survival, cytotoxic chemotherapy has a useful role in symptom relief. ${ }^{51}$ Efforts in this direction must be encouraged. Cachexia is often a distressing symptom in patients with cancer and attempts have been made to use drugs to improve nutrition. Medroxyprogesterone acetate has been evaluated by a double blind, randomised, placebo controlled trial in 41 patients with advanced cancer. The patients receiving medroxyprogesterone acetate had a significant improvement in appetite and in protein indicators of nutrition-namely, serum thyroid binding prealbumin and retinol binding protein. The improvement was seen in patients with small cell lung cancer and in patients with other malignancies. ${ }^{52}$ In a similarly designed trial patients with unresectable non-small cell lung cancer receiving hydrazine sulphate had a higher energy intake and serum albumin con- centration than the placebo group. The median duration of survival was 292 days in the group having hydrazine sulphate compared with 187 days in the placebo group but this difference was not statistically significant. ${ }^{53}$

\section{Conclusion}

Prospects for conventional treatment of lung cancer remain poor. Developments in biology, however, suggest new targets for treatment. Current research must be designed in such a way as to allow useful drugs to be identified and ineffective drugs to be excluded in well designed clinical trials. The trials must allow new drugs to be tested as quickly as possible, early in the natural history of the disease, but at the same time they must give the patient the best chance of a good quality of life and the possibility of prolonged survival.

1 Office of Population Census and Surveys. Cancer Statistics: Registrations, England \& Wales 1983. London: HMSO, 1986.

2 Souhami R, Law K. Longevity in small cell lung cancer. A report to the Lung Cancer Subcommittee of the United Kingdom Coordinating Committee for Cancer Research. Br J Cancer 1990;61:584-9.

3 Splinter TAW. Chemotherapy in advanced non-small cell lung cancer. Eur J Cancer 1990;26:1093-9.

4 Joss RA, Cavalli F, Goldhirsch A, et al. New drugs in small cell lung. Cancer Treat Rev 1986;13:157-76.

5 Clark P, Talbot D, Price C, et al. Single agent etoposide in untreated extensive small cell lung cancer [abstract]. Lung Cancer 1988;4:108.

6 Issell BF, Einhorn LH, Comis RL, et al. Multicenter phase II trial of etoposide in refractory small cell lung cancer. Cancer Treat Rev 1985;69:127-8.

7 Bork E, Hansen M, Dombernowsky $\mathrm{P}$, et al. Teniposide (VM-26), an overlooked highly active agent in SCLC: results of a phase II trial in untreated patients. J Clin Oncol 1986;4:524-7

8 Creech RH, Tritcher D, Ettinger DS, et al. Phase II study of PALA, amsacrine, teniposide and zinostatin in small cell lung cancer (EDT 2579). Cancer Treat Rep 1984;68: $1183-4$.

9 Smith IE, Harland SJ, Robinson BD, et al. Carboplatin: a very active new cisplatin analogue of small cell lung cancer. Cancer Treat Rep 1985;69:43-6.

10 Cullen MH, Smith SR, Benfield GFA, Woodruffe CM Testing new drugs in untreated small cell lung cancer may prejudice the results of standard practice: a phase II study of oral idarubicin in extensive disease. Cancer Treat Rep 1987;71:1227-30.

11 Lund B, Hansen F, Hansen M, et al. Phase II study of 1,2,4 triglycidylurazol (TGU) in previously untreated and treated patients with small lung cancer. Eur J Cancer Clin Oncol 1987;23:1031-3.

12 Malik STA, Rayner H, Fletcher J, et al. Phase II trial of mitoxantrone as first-line chemotherapy for extensive mitoxantrone as first-line cer Treat Rep 1987;71:1291-2.

13 Jackson D, Cruz J, White D, et al. Cisplatin in extensive small cell lung cancer: a randomised trial by the Piedmont Oncology Association [abstract]. Proc Am Soc Clin Oncol 1989;8:222.

14 Cohen EA, Gralla RJ, Kris MG, et al. Phase II studies in small cell lung cancer: an analysis of 97 trials [abstract]. Proc Am Soc Clin Oncol 1985;4:1190.

15 Ettinger DS. Evaluation of new drugs in untreated patients with small cell lung cancer: its time has come. J Clin Oncol 1990;8:374-7.

16 Gottlieb JA, Luce JK. Treatment of malignant melanoma with camptothecin (NSC-100880). Cancer Chemother Rep 1972;56:103-6.

17 Ohno R, Okada K, Masoaka T, et al. An early phase II study of CPT-11: a new derivative of camptothecin for the of CPT-11: a new derivative of camptothecin for the treatment

18 Negoro S, Fukuoka M, Niitani $H$, et al. Phase II study of CPT-11, new camptothecin derivative in small cell lung cancer [abstract]. Proc Am Soc Clin Oncol 1991;10:241.

19 Chabot GG, Barilero I, Armand JP, et al. Pharmacokinetics of the camptothecin analogue CPT-11 and its active metabolite SN38 in cancer patients [abstract]. Proc Am Assoc Cancer Res 1991;32:175.

20 Blackstein M, Eisenhauer EA, Wierzbicki R, Yoshida S. Epirubicin in extensive small cell lung cancer: a phase II study in previously untreated patients: a National Cancer Institute of Canada Clinical Trials Group Study. J Clin Oncol 1990;8:385-9.

21 Eckhardt S, Kolaric K, Vukas D, et al. Phase Ii study of 4'- 
epi-doxorubicin in patients with untreated extensive small cell lung cancer. South-Eastern European Oncology Group. Med Oncol Tumor Pharmacother 1990;7:19-23.

22 Ross WE, Sullivan DM, Chow KC. Altered function of DNA topoisomerase as a basis for antineoplasia drug action. In: De Vita V, Hellman S, Rosenberg S, eds. Important Advances in Cancer Oncology. Philadelphia: Lippincott 1987:65-81.

23 Slevin ML, Clark PI, Osborne RJ, et al. A randomised trial to evaluate the effect of schedule in the activity of etoposide in small cell lung cancer [abstract]. Proc Am Soc Clin Oncol 1986;5:175.

24 Einhorn LH, Pennington K, McClean J. Phase II trial of daily oral VP16 in refractory small cell lung cancer: a Hoosier Oncology Group Study. Semin Oncol 1990;17 (suppl 1):32-5.

25 Einhorn LH. Ifosfamide in small cell lung cancer. Semin Oncol 1989;16(suppl 3):19-21.

26 Cantwell BMJ, Bozzini JM, Corris P, et al. Ifosfamide after VP16, doxorubicin and vincristine for small cell lung cancer. Eur J Cancer Clin Oncol 1988;24:123-9.

27 Loehrer PR, Birch R, Kramer BS, et al. Ifosfamide in the treatment of small cell lung cancer and non-small cell lung cancer. An SECSG Trial. Cancer Treat Rep 1986;1: 919-20.

28 Smith IE, Perren TJ, Yarnold JR, et al. Carboplatin, VP16 and ifosfamide, intensive chemotherapy for small cell lung cancer: a phase II study. Proceedings of the 5th World Conference on Lung Cancer, Interlaken, 1988 [Abstract 104].

29 Thatcher $N$, Lind $M$. Carboplatin in small cell lung cancer. Semin Oncol 1990;17(suppl 2):40-8.

30 Clamon G, Goutsou M, Perry MC, Lyss A, Green MR. Interleukin-2 in extensive small cell lung cancer: a preliminary suggestion of activity [abstract]. Proc Am Soc Clin Oncol 1991;10:267.

31 Fukuoka M, Negoro S, Niitani H, Taguchi T. A phase II study of a new camptothecin derivative, CPT-11 in previously untreated non-small cell lung cancer [abstract]. Proc Am Soc Clin Oncol 1990;9:226.

32 Depierre A, Lemarie E, Dabouis G, et al. Efficacy of navelbine in non-small cell lung cancer. Semin Oncol 1989;16:26-9.

33 Jones AL, Smith IE. Zeniplatin (CL 286,588), an active new platinum analogue in advanced non-small cell lung cancer [abstract]. Proc Am Soc Clin Oncol 1991;10:268.

34 Shum KY, Kris MG, Gralla RJ, Burke MT, Marks LD, Heelan RT. Phase Ii study of 1-ethyl-10-deaza-aminopterin in patients with stage III and IV non-small cell lung cancer. J Clin Oncol 1988;6:446-50.

35 Soulhami R, Hartley J, Allen R, Rudd R, Harper P, Spiro S. Phase II study of 10-Edam (10-ethyl-10-deazaaminopterin) in untreated advanced non-small cell lung cancer [abstract]. Proc Am Soc Clin Oncol 1991;10:252.

36 Bertino JR, Lin JT, Cashmore AR, et al. Clinical pharmacology and metabolism of trimetrexate. Semin Oncol 1988;15:8-9.

37 Maroun J. Clinical response to trimetrexate as sole therapy for non-small cell lung cancer. Semin Oncol 1988;15(suppl 2):17-21.

38 Anderson $\mathrm{H}$, Lund B, Hansen $\mathrm{HH}$, Walling J, Thatcher $\mathrm{N}$. Gemcitabine in non-small cell lung cancer [abstract]. Proc Am Soc Clin Oncol 1991;10:247

39 Monnier A, Pujol JL, Cerrina ML, et al. Fotemustine in non-small cell lung cancer: phase II study in 32 patients with poor prognostic factors [abstract]. Proc Am Soc Clin Oncol 1991;10:248.

40 Sorensen JM, Bach F, Dombernowski P, Vibe-Petersen J, Hansen JJ. TCNU in adenocarcinoma of the lung: a phase II study with divided doses. Ann Oncol 1990;1:299-300.

41 Krigel $R$, Lynch E, Kucuk O, et al. Interleukin-2 (IL-2) therapies prolong survival in metastatic non-small cell lung cancer. Proc Am Soc Clin Oncol 1991;10:246.

42 Yang SC, Owen-Schaub L, Mendiguren-Rodriguez A, Grimm EA, Hong WK, Roth JA. Combination immunotherapy for non-small cell lung cancer. Results with interleukin-2 and tumour necrosis factor- $\alpha$. J Thorac interleukin-2 and tumour necro.

43 Johnson BE, Ihde DC, Makuch RW, et al. Myc family oncogene amplification in tumour cell lines established from small cell lung cancer patients and its relationship to clinical status and course. J Clin Invest 1987;79:1629-34.

44 Boys SC, Kok K, ven der Veen AY, et al. A deletion at $3 \mathrm{p}$ is common to all major types of lung cancer. Lung Cancer 1987;3:107-9.

45 Miller YE, Sullivan N, Gazdar A. Reduced or absent aminoacyclase-I activity in small cell lung cancer: evidence for inactivation of genes encoded by chromosome 3 p. Clin Res 1986;34:568.

46 Wickstrom EL, Bacon JA, Gonzalez A, et al. Human promyelocytic leukaemia HL-60 cell proliferation and cmyc protein expression are inhibited by an antisense pentadece nucleotide targetted against c-myc mRNA pentadeca nucleotide targetted against c-myc mRNA

47 Macaulay VM, Everard MJ, Teale JD, et al. Autocrine function for insulin-like growth factor $I$ in human small cell lung cancer cell lines and fresh tumour cells. Cancer Res 1990;50:2511-7.

48 Cuttitta F, Carney DN, Mulshine J, et al. Bombesin-like peptides can function as autocrine growth factors in human small cell lung cancer. Nature 1985;316:823-6.

49 Drings $P$, Fischer JR. Biology and clinical use of.GMCSF in lung cancer. Lung 1990;168(suppl):1059-68.

50 Metcalf $D$. The colony stimulating factors, discovery, development and clinical applications. Cancer 1990;65: 2185-206.

51 Hardy JR, Noble T, Smith IE. Symptom relief with moderate dose chemotherapy (mitomycin C, Vinblastine, cisplatin) in advanced non-small cell lung cancer. $\mathrm{Br} J$ Cancer 1989;60:764-6.

52 Talbot DC, Joel SP, Stubbs L, et al. A randomised, double blind, placebo controlled trial of medroxyprogesterone acetate (MPA) in cancer cachexia. 3rd Annual Meeting of ACP [poster]. Br J Cancer 1988;58:267.

53 Chlebowski RT, Bulcavage L, Grosvenor $M$, et al. Hydrazine sulfate influence on nutritional status and survival in non-small cell lung cancer. J Clin Oncol 1990;8:9-15.

54 Evans WK, Eisenhauer EA, Cormier Y, et al. Phase II study of amonafide: results of treatment and lessons learned from the study with extensive small cell lung cancer. $J$ Clin Oncol 1990;8:390-5.

55 Simon MS, Eckenrode J, Natale RB. Phase II trial of methylglyoxal bisguanylhydrazone (MGBG) in refractory small cell lung cancer. Invest New Drugs 1990;8(supp 1):79-81.

56 Shepherd F, Eisenhauer E, Stewart D, et al. NCI Canada phase II studies of sulofenur in untreated small cell lung and renal cancers [abstract]. Proc Am Soc Clin Oncol 1991;10:251.

57 Lad TE, Blough RR, Everard M, et al. Phase II trial of spirogermanium in advanced non-small cell lung cancer. Invest Newo Drugs 1989;7:223-4.

58 Holoye PY, Carr DT, Dhingra HM, et al. Phase II study of tiazofurin (NSC286193) in the treatment of advanced small cell bronchogenic carcinoma [abstract]. Invest Nero Drugs 1988;6:217.

59 Giaccone G, Donadio M, Bonardi G, et al. Teniposide in the treatment of small cell lung cancer. The influence of prio chemotherapy. J Clin Oncol 1988;6:1264-70.

60 Kramer BS, Birch R, Greco A, et al. Randomised phase I evaluation of iproplatin and carboplatin in lung cancer. Am J Clin Oncol 1988;11:643-5.

61 Ettinger DS, Finkelstein DM, Abeloff MD, Bonomi PD Justification for evaluating new anticancer drugs in selected untreated patients with a chemotherapy-sensitive advanced cancer: an ECOG randomised study [abstract] Proc Am Soc Clin Oncol 1990;9:224.

62 Harding M, Docherty V, Mackie R, Dorward A, Kaye S Phase II studies of mitoxolomide in melanoma, lung and ovarian cancer. Eur J Cancer Clin Oncol 1989;25:785-8.

63 Drings P, Gunther IU, Gatzemeier U, et al. Pirarubicin in advanced non-small cell lung cancer. $A$ trial of the phase I/II study group of the Association for Medical Oncology of the German Cancer Society. Onkologie 1990;13:180-4.

64 Rose C, Lad TE, Kilton LJ, et al. Phase II trial of 4'deoxydoxorubicin for unresectable non-small cell bronchogenic carcinoma. An Illinois Cancer Council study. Invest New Drugs 1990;8:97-9.

65 Gatzemeier U, Drings P, Edler L, et al. Chemotherapy with tauromustine in advanced non-small cell lung cancer. A trial of the phase II study group of the Association for Medical Oncology of the German Cancer Society. Onkologie 1990;13:186-8.

66 Okron O, Maca S, De Gregorio M, Ciottoli GB. Phase II study of lonidamine in non-small cell lung cancer: final report. Br J Cancer 1990;61:316-8.

67 Munshi NC, Seitz DE, Fossella F, Lippman SM, Einhorn LH. Phase II study of sulofenur (LY 186641), a nove antineoplastic agent in advanced non-small cell lung cancer [abstract]. Proc Am Ass Cancer Res 1991;32:189.

68 Rigas JR Tong W, Kris MG, Baltzer L, Young CW Warrell TP. Chloroquinoxaline sulfonamide: a phase study of a unique agent with preclinical and clinical activity in non-small cell lung cancer [abstract]. Proc Am Soc Clin Oncol 1991;10:265.

69 Feld R, Wierzbicki R, Walde D, et al. A phase II trial of high dose epirubicin in patients with untreated extensive nonsmall cell lung cancer [abstract]. Proc Am Soc Clin Oncol 1990;2:240.

70 Chachoua A, Krigel R, Schiller JH, Wadler S, Kirkwood J, Blum RH. Phase II study of combination interferon bet and gamma in patients with non-small cell lung cancer. A ECOG pilot study. Proc Am Soc Clin Oncol 1990;9:242.

71 Manegold C, Bischoff H, Fischer JR, Peukert M, Schmahl A Drings P. Phase I/II trial of oral ifosfamide/mesna in advanced non-small cell lung cancer [abstract]. Proc $A m$ Soc Clin Oncol 1990;9:245.

72 Giaccone G, Donadio M, Ferrati P, et al. Teniposide in the treatment of non-small cell lung carcinoma. Cancer Treat Rep 1987;71:83-5.

73 Fukuda M, Shinkai I, Eguchi K, et al. Phase II study of (glycolate-0,0') diammineplatinum (II), a novel platinum complex in the treatment of non-small cell lung cancer. Cancer Chemother Pharmacol 1990;26:393-6.

74 Gatzemeier U, Heckmayr $M$, Hossfeld DK, Zschaber $R$ Achterrath W, Lenaz L. Phase II study of carboplatin in untreated, inoperable non-small cell lung cancer. Cancer Chemother Pharmacol 1990;26:369-72.

75 Ettinger DS, Finkelstein DM, Donehower RC, et al. Phase II study of $\boldsymbol{N}$-methylformamide, spirogermanium and 4 demethoxydaunorubicin in the treatment of non-small cell lung cancer. An Eastern Cooperative Group Study. Med Paed Oncol 1989;17:197-201. 